\title{
Clinicopathological Findings in Suspected Cases of Virus-induced Neoplastic Diseases in Commercial Layer Chickens in Nigeria
}

\author{
Nuhu Abdulazeez Sani ${ }^{1 *}$, Chukwuebuka Iniobong Ugochukwu ${ }^{2}$, Samson Eneojo Abalaka ${ }^{1}$, Ahmadu Saleh $^{3}$, \\ Muhammed Shuaib Muhammed ${ }^{3}$, Sunday Blessing Oladele ${ }^{3}$, Paul Ayuba Abdu ${ }^{4}$, and Celestine Njoku ${ }^{5}$ \\ ${ }^{I} P M B$ 117, Department of Veterinary Pathology, Faculty of Veterinary Medicine, University of Abuja, Abuja, Nigeria \\ ${ }^{2}$ PMB 41001, Department of Veterinary Pathology and Microbiology, Faculty of Veterinary Medicine, University of Nigeria, Nsukka, Nigeria \\ ${ }^{3}$ PMB 1044, Department of Veterinary Pathology, Faculty of Veterinary Medicine, Ahmadu Bello University, Zaria, Kaduna State, Nigeria \\ ${ }^{4}$ PMB 1044, Department of Veterinary Medicine, Faculty of Veterinary Medicine, Ahmadu Bello University, Zaria, Kaduna State, Nigeria \\ ${ }^{5}$ PMB 2084, Department of Veterinary Pathology, Faculty of Veterinary Medicine, University of Jos, Jos, Plateau State, Nigeria \\ "Corresponding author’s Email: nuhu.sani@uniabuja.edu.ng; ORCID: 0000-0002-6351-2535
}

\begin{abstract}
Avian neoplastic diseases, including Marek's disease (MD), avian leukosis (AL), and reticuloendotheliosis (RE), are of economic importance in the chicken industry. However, it is difficult to differentiate MD from AL and RE by clinical signs and postmortem examination. Therefore, the present study aimed to classify the avian neoplastic diseases affecting commercial layer chickens in Nigeria using clinical history, postmortem examination, and histopathological technique. Carcasses of commercial layer chickens from 7 and 20 poultry farms in Kaduna and Plateau States were studied, respectively, from February 2017 to March 2018. The age, morbidity, and mortality rates in each of the affected farms were determined. Detailed postmortem examinations were carried out on the carcasses from the affected farms, and organs observed to have neoplastic lesions were fixed in $10 \%$ neutral buffered formalin for histopathology. The age means of the affected layers were 20.6 weeks and 20.8 weeks in Kaduna and Plateau States, respectively. The average morbidity rates of neoplasm in the affected layers were $3.9 \%$ and $9.3 \%$ in Kaduna and Plateau States, respectively, while the average mortality rates were $8.6 \%$ and $8.5 \%$ in Kaduna and Plateau States, respectively. The clinical observation of affected chickens indicated that they were anorexic and emaciated. Generally, the neoplastic lesions were characterized by white to gray, multifocal, firm nodules of varying sizes on the affected organs. In Kaduna State, the neoplasms were commonly observed on the liver $(85.7 \%)$, spleen $(71.4 \%)$, heart (42.9\%), and kidneys (42.9\%), while in Plateau State, the affected organs included liver (50\%), spleen (25\%), proventriculus $(25 \%)$ and lungs $(25 \%)$. The histopathological changes in the affected tissues were similar and characterized predominantly by the infiltration of lymphocytes, lymphoblasts, and macrophages. The patterns of distribution of the pleomorphic neoplastic cells within the liver were multifocal and perivascular in most cases. Findings from the current study indicated that cases of neoplasms in commercial layer chickens in Kaduna and Plateau States, Nigeria, could be attributed to MD.
\end{abstract}

Keywords: Avian neoplastic diseases, Layer chickens, Pathology

\section{INTRODUCTION}

Avian neoplastic diseases, including Marek's disease (MD), avian leukosis (AL), and reticuloendotheliosis (RE), are of economic importance (Payne and Venugopal, 2000). The clinical signs of these diseases are in most cases not pathognomonic and include inappetence, abnormal feathering, paleness of comb and wattles, emaciation, depression, paralysis, and death (Okoye et al., 1993; Abdel-Latif and Khalafalla, 2005). In addition to encouraging tumor growth, avian neoplastic disease viruses may induce immunosuppression and other production problems including reduced growth rate and livability, decreased fertility and hatchability, and decreased egg production in an affected flock (Palya et al., 2000; El-Sebelgy et al., 2014; Zeghdoudi et al., 2017).

Available literature indicates that there was an increase in outbreaks of virus-induced avian neoplastic diseases in Kaduna and Plateau States, and most of the outbreaks have been attributed to Marek's disease, despite vaccination of commercial layer chickens (Wakawa et al., 2012; Sani et al., 2017). Diagnosis of virus-induced avian neoplastic diseases in Kaduna and Plateau States have 
mostly been by clinical observations and gross examination of carcasses for tumors (Jwander et al., 2013; Musa et al., 2013; Sani et al., 2017). Gross examination of neoplastic tissues in most cases cannot be relied upon to differentiate one virus-induced avian neoplastic disease from another (Dong et al., 2015; Meng et al., 2018). However, MD, AL, and RE have distinct histopathological changes that may be used to differentiate MD from AL and RE, hence the present study was set up for that. Therefore, the current study aimed to classify the neoplastic diseases affecting commercial layer chickens in Kaduna and Plateau States, Nigeria using clinical history, postmortem examination, and histopathological technique. Results from this study provided insights on the neoplastic diseases affecting commercial layer chickens in Kaduna and Plateau States, Nigeria, which is pivotal in instituting control measures for the diseases.

\section{MATERIALS AND METHODS}

\section{Ethics committee approval}

The research protocol was approved by the University of Abuja Ethics Committee on Animal Use (UAECAU), with the assigned number: UAECAU/2017/0020.

\section{Study areas}

The study was carried out in Kaduna and Plateau States, Nigeria. The Nigeria Galleria (2015) described Kaduna State as located at the center of Northern Nigeria, and comprised 23 Local Government Areas. Kaduna State is located between latitudes $9^{\circ} 03^{\prime}$ and $11^{\circ} 32^{\prime} \mathrm{N}$ and longitudes $6^{\circ} 05^{\prime}$ and $8^{\circ} 38^{\prime} \mathrm{E}$ of the Greenwich Meridian (Kaduna State, 2019). Kaduna State shares boundaries with Federal Capital Territory, Abuja and Nasarawa State to the south, Bauchi and Plateau States to the east, Niger State to the west, and Zamfara, Katsina, and Kano States to the North. Plateau State is in North Central, Nigeria, and is located between latitude $80^{\circ} 24 \mathrm{~N}$ and longitudes $80^{\circ} 32^{\prime}$ and $100^{\circ} 38^{\prime} \mathrm{E}$ (Plateau State, 2019). The State shares boundary with Bauchi State to the Northeast, Kaduna State to the Northwest, Nasarawa State to the Southwest, and Taraba State to the Southeast (NIPC, 2019).

\section{Selection of commercial layer chickens' farms for the study}

A total of 7 layer farms (designated Z1 to Z7) and 20 layer farms (designated J1 to J20) in Kaduna and Plateau States were selected for the study, respectively, in which neoplastic lesions were observed during the postmortem examination of carcasses. The seven commercial layer chickens' farms studied in Kaduna State were cases reported to the Poultry Clinic of the Veterinary Teaching Hospital, Ahmadu Bello University, Zaria, during the study period. The 20 farms studied in Plateau State were cases reported to the Evangelical Church Winning All Veterinary Clinic, Bukuru, Jos South, during the study. The seven farms in Kaduna State had commercial layer chickens with flock sizes ranging from 323 (farm Z4) to 907 (farm Z3) with an average flock size of 581.1 chickens. The 20 farms in Plateau State had commercial layer chickens with flock sizes ranging from 86 (farm J19) to 4703 (farm J9) with an average flock size of 872.9 chickens. The information about the affected layer flocks, such as the age, vaccination history against MD, morbidity and mortality rates as well as the rate of egg production were documented. The study lasted 13 months, from February 2017 to March 2018.

\section{Gross pathology}

Detailed postmortem examination of carcasses of commercial layer chickens from the farms affected with avian neoplastic diseases in Kaduna and Plateau States was carried out according to the method described by Collett et al. (2020). The lesions observed on the organs (liver, spleen, proventriculus, intestine, pancreas, mesentery, kidneys, heart, lungs, sciatic nerve, and ovary) were properly described based on the changes in their size, shape, color, consistency, and distribution of the lesions (Brown, 2012), and promptly documented. Lesions that were firm, nodular to diffuse, white to grey, deep or superficial with smooth surface were considered neoplastic (Duguma et al., 2005). It was ensured that personal protective equipment, such as gloves, coveralls, and boots, were used throughout the necropsy. Photographs of the lesions were taken using a digital camera (SONY ${ }^{\circledR}$ Cybershot, 16.2 megapixels, DSC-TX20 model, Japan).

\section{Histopathology}

The tissues observed to have neoplasms at postmortem from carcasses of commercial layer chickens with suspected cases of virus-induced neoplastic diseases in the study areas were subjected to standard histopathological procedures as described by Aughey and Frye (2001) at the Histopathology Laboratory, Department of Veterinary Pathology, Faculty of Veterinary Medicine, ABU, Zaria. The slides were examined for features of neoplasia which included a high mitotic index, nuclear hyperchromacia, cellular pleomorphism, and cell types 
(Payne and Venugopal, 2000) using a light microscope at different magnifications (X40, X100, X200, and X400). Photomicrographs of the changes observed in each slide were taken with a digital camera (SONY ${ }^{\circledR}$ Cybershot 16.2 megapixels, DSC-TX20 model, Japan), transferred to a computer and labeled appropriately.

\section{Data analysis}

The mean ages of the affected commercial layer chickens in Kaduna and Plateau States were determined. The egg production, morbidity, and mortality rates of the affected layer chickens in Kaduna and Plateau States at the time of sampling were summarized into percentages using descriptive analysis in the Statistical Package for Social Sciences (SPSS) software version 22.

\section{RESULTS}

\section{Clinical history}

The most common clinical manifestations of affected chickens in the farms in both states were anorexia, emaciation, ruffled feathers, somnolence, and shriveled combs and wattles. The age range of the commercial layer chickens in the seven farms from Kaduna State was from 12 weeks (farm Z6) to 31 weeks (farm Z4) with an average age of 20.6 weeks. The commercial layer chickens in four farms (Z1, Z2, Z3, and Z7) in Kaduna State were vaccinated against $M D$, while the vaccination history of commercial layer chickens in the other farms $(\mathrm{Z4}, \mathrm{Z5}$, and Z6) could not be ascertained. The morbidity of neoplastic disease in the commercial layer chickens in Kaduna State ranged from $0.7 \%$ (farm $\mathrm{Z} 3$ ) to $12.3 \%$ (farm $\mathrm{Z} 1$ ) with an average morbidity rate of $3.9 \%$, while the mortality ranged from $2.6 \%$ (farm Z1) to $16.5 \%$ (farm Z6) with an average mortality rate of $8.6 \%$. The average level of egg production by the commercial layer chickens from the seven farms in Kaduna State was 62\% (Table 1).

The age range of the commercial layer chickens in the 20 farms from Plateau State was 11 weeks (farms J4 and J8) to 39 weeks (farm 11) with an average age of 20.8 weeks. Fourteen of the farms only in Plateau State were vaccinated against MD. The morbidity rates of neoplastic disease in the commercial layer chickens from the farms in Plateau State were within the range of $1.1 \%$ (farm J11) to $33 \%$ (farm J20) with average morbidity of $9.3 \%$, while mortality ranged from $1.6 \%$ (farm $\mathrm{J} 11$ ) to $22.3 \%$ (farm J3) with an average mortality of $8.5 \%$. The average level of egg production by the commercial layer chickens in the 20 farms in Plateau State was 65.5\% (Table 2).

\section{Gross lesions}

The neoplastic lesions were characterized by white to gray, multifocal, firm nodules of varying sizes on the affected organs. Marked enlargement of the affected organs was also observed. In Kaduna State, the organs of carcasses of commercial layer chickens were observed grossly to have neoplasms, included the liver $(85.7 \%)$, spleen $(71.4 \%)$, heart $(42.9 \%)$, kidney $(42.9 \%)$, mesentery $(28.6 \%)$, proventriculus $(14.3 \%)$, lung $(14.3 \%)$, intestine $(14.3 \%)$, and pancreas $(14.3 \%)$. Other observed gross lesions included emaciated carcasses $(85.7 \%)$, enlarged liver $(85.7 \%)$, spleen $(71.4 \%)$, proventricular glands (71.4\%), kidneys $(57.1 \%)$, and sciatic nerve $(14.3 \%)$. Petechial hemorrhages were observed on the mucosa of the proventriculus $(71.4 \%)$ and caecal tonsils (14.3\%). The ovarian follicles atrophied in all the carcasses of the commercial layer chickens that were laying.

In Plateau State, the organs of carcasses of commercial layer chickens were observed grossly to have neoplasms, included the liver (50\%), spleen (25\%), proventriculus $(25 \%)$, lung $(25 \%)$, kidney $(15 \%)$, intestine $(10 \%)$, heart $(5 \%)$ and mesentery $(5 \%)$. Other observed gross lesions were emaciated carcasses (95\%), hepatomegaly (85\%), enlarged proventricular glands $(60 \%)$, splenomegaly $(40 \%)$, renomegaly $(15 \%)$, and enlarged sciatic nerve $(10 \%)$. Petechial hemorrhages were detected on the mucosa of the proventriculus $(35 \%)$, caecal tonsils $(25 \%)$ and intestine $(15 \%)$. The ovarian follicles atrophied in all the carcasses of the commercial layer chickens that were laying.

\section{Histopathology}

The infiltrating neoplastic cells in the affected organs were pleomorphic, comprising small, medium and large lymphocytes, macrophages, and plasma cells. The distributional patterns of the pleomorphic neoplastic cells within the liver of commercial layer chickens from Kaduna State were multifocal $(85.7 \%)$ and perivascular $(85.7 \%)$. Other histopathologic changes observed in the livers included degeneration and necrosis of the hepatocytes $(100 \%)$, congested blood vessels (100\%), thick vascular walls (57.1\%), dissociated hepatic cords $(57.1 \%)$, and hemorrhage within the parenchyma (14.3\%).

On the other hand, the distributional patterns of the pleomorphic neoplastic cells within the liver of commercial layer chickens from Plateau State were multifocal $(70 \%)$, perivascular $(50 \%)$, diffuse $(20 \%)$, and coalescing $(5 \%)$. Other histopathologic changes observed in the livers included degeneration and necrosis of the hepatocytes (95\%), congested blood vessels (35\%), dissociated hepatic cords $(30 \%)$, and hemorrhage within the parenchyma $(5 \%)$. 


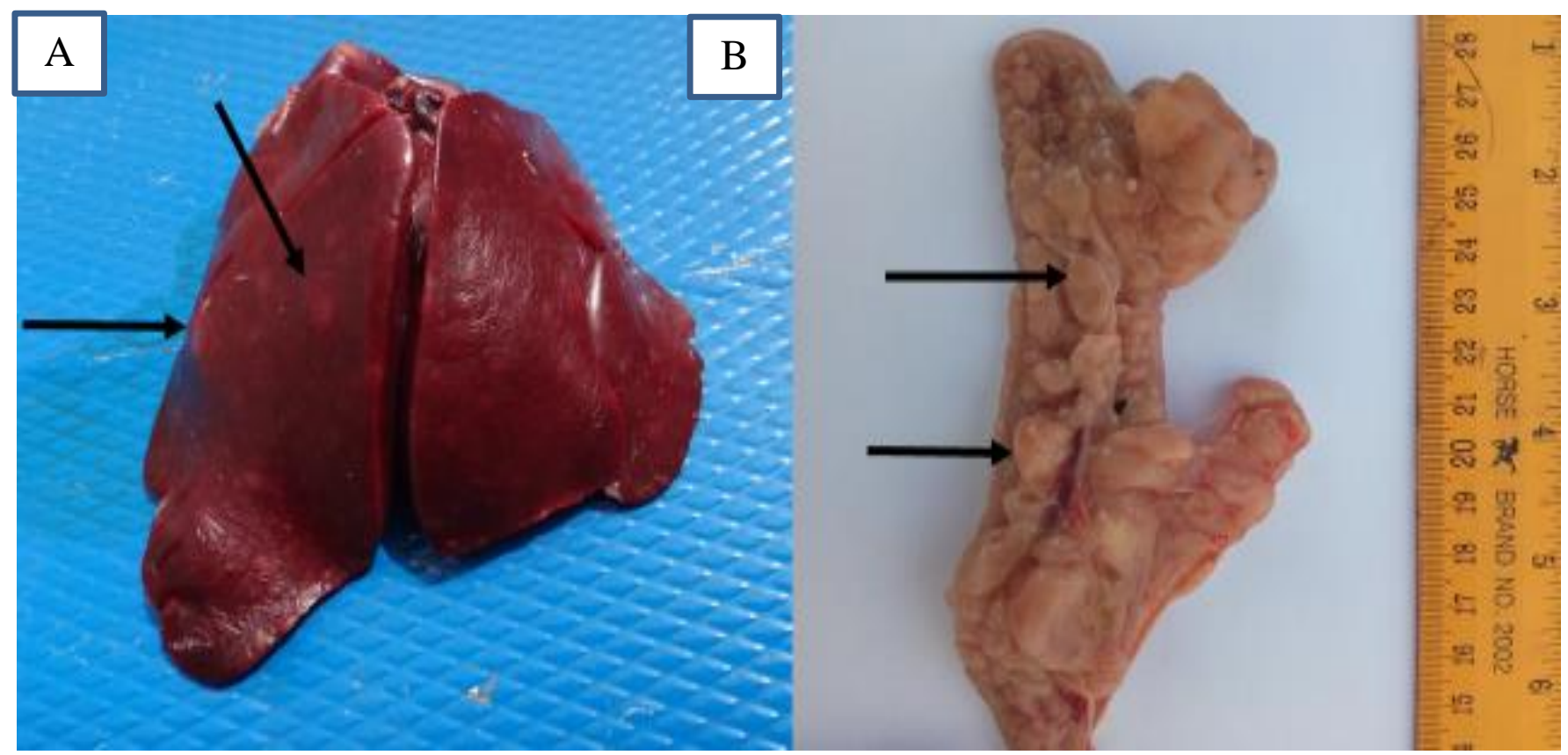

Figure 1. A: Liver of a 14-week-old commercial layer chicken (Z1). Note the hepatomegaly and white to gray, multifocal, firm neoplastic nodules of varying sizes ranging from 0.2 to $1.0 \mathrm{~cm}$ in diameter (arrows) affecting all the lobes of the liver. B: Intestine (duodenum) of a 27-week-old commercial layer chicken (Z3). Note the yellow, nodular neoplastic growths ranging from 0.2 to $2.0 \mathrm{~cm}$ in diameter, involving the pancreas and the mesentery (arrows).

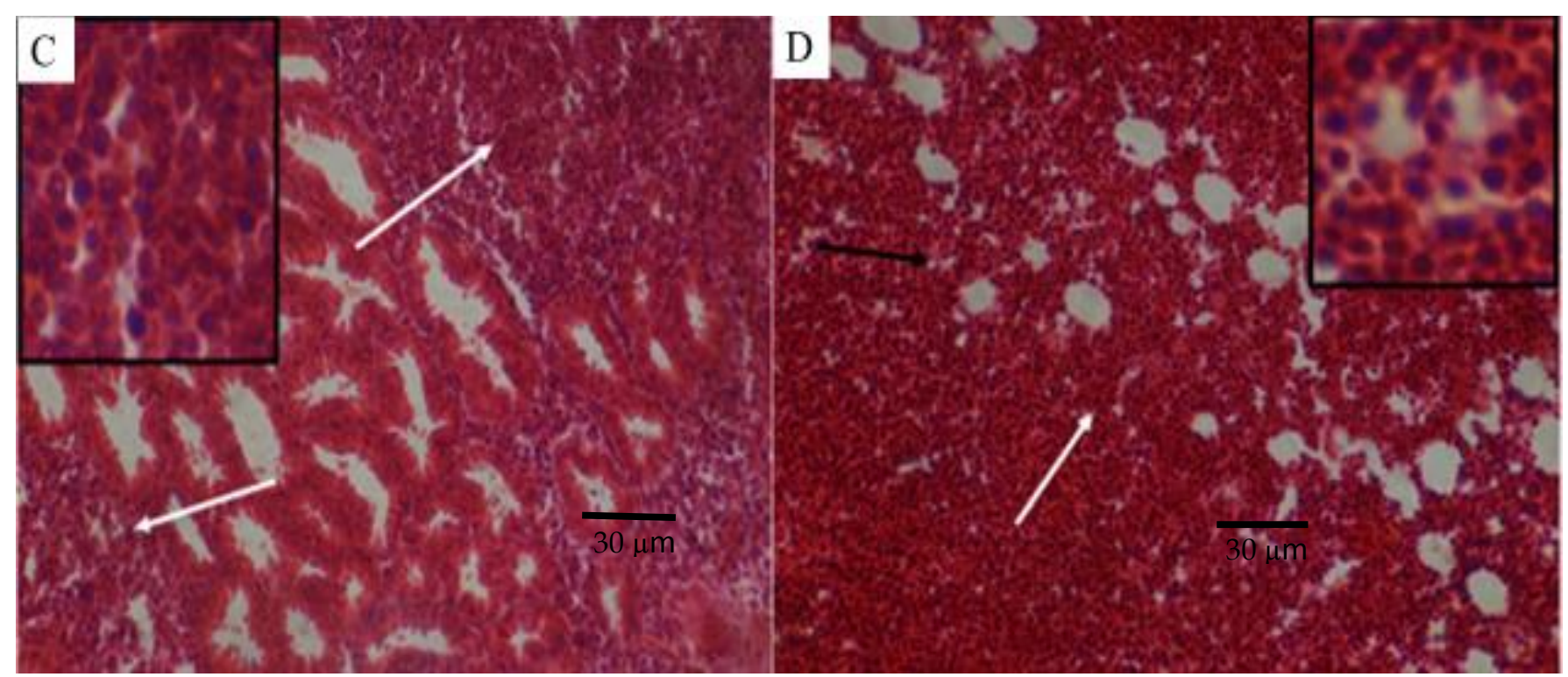

Figure 2. A: Photomicrograph of the section of the liver of a 37-week-old commercial layer chicken affected by the neoplastic disease (J6). Note the multifocal aggregates of neoplastic mononuclear cells predominantly lymphocytes (arrows and insert); H \& E stain, $30 \mu \mathrm{m}$. B: Photomicrograph of the section of the heart of a 12-week-old commercial layer chicken (J15). Note the neoplastic mononuclear cellular infiltrates, predominantly lymphocytes (black arrow and insert), crowding out the fragmented cardiomyocytes (white arrow); H \& E stain, $30 \mu \mathrm{m}$. C: Photomicrograph of the section of the proventriculus of a 12-week-old commercial layer chicken (J15). Note the neoplastic mononuclear cells predominantly lymphocytes (white arrows and insert), and hyperplasia of the epithelial cells of the glands; H \& E stain, $30 \mu \mathrm{m}$. D: Photomicrograph of the section of lung of a 13-week-old commercial layer chicken (J19). Note the neoplastic mononuclear cells predominantly lymphocytes, occluding the air sacs (black arrow and insert). The inter air sac walls were also thickened (white arrow), $\mathrm{H} \& \mathrm{E}$ stain, $30 \mu \mathrm{m}$. 
Table 1. Morbidity and mortality rates and the level of egg production of commercial layer chickens from the farms with neoplastic diseases in Kaduna State, Nigeria.

\begin{tabular}{|c|c|c|c|c|c|c|}
\hline Farm & Age (weeks) & Flock size & MDVS & Morbidity (\%) & Mortality (\%) & $\operatorname{EP}(\%)$ \\
\hline $\mathrm{Z1}$ & 14 & 640 & Vaccinated & $22(3.4)$ & $17(2.6)$ & NA \\
\hline $\mathrm{Z} 2$ & 16 & 480 & Vaccinated & $12(2.5)$ & $28(5.8)$ & NA \\
\hline $\mathrm{Z} 4$ & 31 & 323 & Unknown & $17(5.3)$ & $43(13.3)$ & 63 \\
\hline $\mathrm{Z5}$ & 29 & 542 & Unknown & $9(1.7)$ & $67(12.4)$ & 68 \\
\hline Z6 & 12 & 351 & Unknown & $43(12.3)$ & $58(16.5)$ & NA \\
\hline
\end{tabular}

MDVS: Marek's disease vaccination status, EP: Egg production, NA: Not applicable.

Table 2. Morbidity and mortality rates and the level of egg production of commercial layer chickens from the farms with neoplastic diseases in Plateau State, Nigeria.

\begin{tabular}{|c|c|c|c|c|c|c|}
\hline Farm & Age (weeks) & Flock size & MDVS & $\begin{array}{c}\text { Morbidity } \\
(\%)\end{array}$ & Mortality (\%) & EP $(\%)$ \\
\hline $\mathrm{J} 1$ & 33 & 290 & Vaccinated & $12(4.1)$ & $47(16.2)$ & 62 \\
\hline $\mathrm{J} 2$ & 29 & 180 & Vaccinated & $6(3.3)$ & $13(7.2)$ & 68 \\
\hline $\mathrm{J} 3$ & 17 & 242 & Vaccinated & $31(12.8)$ & $54(22.3)$ & NA \\
\hline $\mathrm{J} 4$ & 11 & 1,304 & Vaccinated & $218(16.7)$ & $174(13.3)$ & NA \\
\hline $\mathrm{J} 5$ & 13 & 3,362 & Vaccinated & $408(12.1)$ & $376(11.2)$ & NA \\
\hline J6 & 37 & 387 & Unknown & $16(4.1)$ & $12(3.1)$ & 72 \\
\hline J7 & 25 & 178 & Unknown & $5(2.8)$ & $11(6.2)$ & 42 \\
\hline $\mathrm{J} 8$ & 11 & 793 & Vaccinated & $23(2.9)$ & $52(6.6)$ & NA \\
\hline J9 & 14 & 4,703 & Vaccinated & $271(5.8)$ & $285(6.1)$ & NA \\
\hline $\mathrm{J} 10$ & 15 & 586 & Vaccinated & $93(15.9)$ & $77(13.1)$ & NA \\
\hline $\mathrm{J} 11$ & 39 & 1,118 & Vaccinated & $12(1.1)$ & $18(1.6)$ & 69 \\
\hline $\mathrm{J} 12$ & 27 & 89 & Unknown & $5(5.6)$ & $8(9.0)$ & 78 \\
\hline $\mathrm{J} 13$ & 13 & 672 & Vaccinated & $108(16.1)$ & $73(10.9)$ & NA \\
\hline $\mathrm{J} 14$ & 14 & 215 & Unknown & $34(15.8)$ & $23(10.7)$ & NA \\
\hline $\mathrm{J} 15$ & 12 & 738 & Vaccinated & $54(7.3)$ & $61(8.3)$ & NA \\
\hline J16 & 27 & 299 & Vaccinated & $13(4.4)$ & $12(4.0)$ & 62 \\
\hline $\mathrm{J} 17$ & 33 & 406 & Unknown & $9(2.2)$ & $8(2.0)$ & 71 \\
\hline $\mathrm{J} 18$ & 16 & 1,261 & Vaccinated & $112(8.9)$ & $87(6.9)$ & NA \\
\hline J19 & 13 & 86 & Unknown & $7(8.1)$ & $13(15.1)$ & NA \\
\hline $\mathrm{J} 20$ & 16 & 548 & Vaccinated & $181(33)$ & 79 (14.4) & NA \\
\hline Average & 20.8 & 872.9 & & $80.9(9.3)$ & $74.2(8.5)$ & 65.5 \\
\hline
\end{tabular}

MDVS: Marek's disease vaccination status, EP: Egg production, NA: Not applicable.

\section{DISCUSSION}

The age range of commercial layer chickens in the farms with cases of avian neoplasm in Kaduna State was 12 to 31 weeks, whereas it was 11 to 39 weeks in Plateau State. This finding was similar to the finding of Gao et al. (2012), where most of the layer chickens with neoplasms associated with AL virus subgroup $\mathrm{J}$ infection were between 15 and 29 weeks of age. In a retrospective study by Musa et al. (2013), $88.7 \%$ of the cases diagnosed as MD were from layer chickens with ages between 11 and 30 weeks. Furthermore, Haq et al. (2001) reported a high prevalence of MD in chickens that were between 13 and 30 weeks old.
The average morbidity rate of avian neoplasm in layer chickens from farms in Kaduna State was 3.9\%, while the average morbidity was $9.3 \%$ in Plateau State. This was in line with previous findings indicating that the morbidity of avian neoplastic diseases was generally low (Okwor and Eze, 2011). Okonkwo (2015) reported the morbidity rate of MD as $4.7 \%$ and $9.5 \%$ in two-layer flocks, whereas Cheng et al. (2010) reported the morbidity rates between 5 and $15 \%$ in cases of avian neoplastic disease due to ALV subgroup $\mathrm{J}$ infection. However, morbidity rate as high as $67.9 \%$ in local chickens that were not vaccinated against MD was reported by Duguma et al. (2005). Similarly, Gao et al. (2010) reported a morbidity rate of $60 \%$ in chickens with ALV subgroup J associated neoplasms. 
In the present study, the average mortality rate of avian neoplastic disease in layer chickens from farms in Kaduna State was $8.6 \%$, whereas it was $8.5 \%$ in Plateau State. A wide range of mortality, ranging from low to high, due to avian neoplastic diseases was commonly observed in affected flocks. While Okonkwo (2015) reported MD related mortality of $2.3 \%$ and $2.7 \%$ in two flocks of layers, Okwor and Eze (2011) reported low mortality due to MD in several flocks of chickens, but up to $25 \%$ mortality in a few flocks, with morbidity and mortality decreasing as the chickens grew older. In unvaccinated local chickens, MD was responsible for a very high mortality of $66.2 \%$ and a case fatality rate of 97.9\% (Duguma et al., 2005). Similar high mortalities have been reported in outbreaks due to AL. Gao et al. (2010) reported a mortality of more than $20 \%$ in a case of hemangioma due to $\mathrm{AL}$ virus subgroup $\mathrm{J}$ infection. Three flocks were reported to have mortalities of $12 \%, 18 \%$, and $20 \%$ due to erythroblastosis (Wang et al., 2013). Zeng et al. (2015) reported a wide range of mortalities in flocks with avian neoplasms when many of the tested chickens having mixed infections with avian neoplastic disease viruses. Mortalities of $16.4 \%$ and $20 \%$ in two flocks of pullets due to RE was reported by Okoye et al. (1993).

In the current study, the liver was also observed to be the most affected organ as reported by some authors (Cheng et al., 2011; Gao et al., 2015). The liver plays an important role in digestion, metabolism, regulating the production, storage and releasing of lipids, carbohydrates, and proteins (Denbow, 2000). These strategically vital functions of the liver may not be carried out when the structural integrity of the liver is severely compromised, as observed in this study.

Pathognomonic lesions for avian neoplastic diseases were not commonly observed in this study. For example, the involvement of peripheral nerves is generally regarded as a pathognomonic lesion observed in chickens with MD. However, this finding was observed in only one (Z3) out of the seven layer chickens' farms with cases of avian neoplasms in Kaduna State, and in only two (J3 and J8) of the layer chickens' farms (20) with cases of avian neoplasms in Plateau State. This situation has made the differential diagnosis of avian neoplastic diseases by gross examination of affected chickens' carcasses almost impossible. The nature of infiltrating neoplastic cells, characterized by cellular pleomorphism comprising lymphocytes, lymphoblasts, macrophages, and neutrophils, was similar in all the organs examined. These histopathological findings were consistent with those observed in cases of MD as reported in many studies
(Mitra et al., 2013; Okonkwo, 2015; Abreu et al., 2016). The distributional pattern of the neoplastic cells was multifocal (85.7\%) and perivascular (85.7\%) in the livers of layer chickens from the farms in Kaduna State, whereas the distribution was multifocal $(70 \%)$, coalescing $(5 \%)$, diffuse $(20 \%)$, and perivascular $(50 \%)$ in the livers from the farms in Plateau State.

Vaccination has been widely used to control MD all over the world. However, the emergence of more virulent strains of MD has made some MD vaccines ineffective (Sun et al., 2017). The majority of the layer chickens' farms with cases of avian neoplastic disease in both Kaduna and Plateau States had a history of vaccination against MD. Although the type of vaccine used by the farmers could not be ascertained, available reports suggest that the Herpesvirus of Turkeys (HVT) vaccines are widely used for the control of MD in the two States (Jwander et al., 2012; Adedeji et al., 2017). In a study by Tian et al. (2011), no difference was observed between HVT vaccinated chickens and unvaccinated chickens in terms of mortality patterns and tumor development. However, no mortality or tumor development was observed in the chickens challenged with a field strain of MDV and vaccinated with Rispens. The presence of immunosuppressive diseases such as chicken infectious anaemia and infectious bursal disease, may also be responsible for MD vaccination failure in chickens (Zhang et al., 2017). These immunosuppressive diseases are endemic in Nigeria (Mbuko et al., 2010; Adedeji et al., 2016).

The average egg production rates of commercial layer chickens from the farms with cases of avian neoplasm in Kaduna State was 62\%. Similarly, the average egg production status of layer chickens from the farms with cases of avian neoplasm in Plateau State was $65.5 \%$. Low egg production in layer chickens from the farms with cases of either $\mathrm{MD}, \mathrm{AL}$, or $\mathrm{RE}$ have been widely reported (Okoye et al., 1993; Abdel-Latif and Khalafalla, 2005; Okonkwo, 2015). Grossly, the ovarian follicles were regressed in all the carcasses from the layer flocks that were in lay, from the farms in Kaduna and Plateau States. This finding suggests the reason for low egg production recorded in the laying flocks with the outbreak of the avian neoplastic disease in the current study.

\section{CONCLUSION}

The clinical history and gross changes in the affected chickens were not pathognomonic, therefore, it could not 
be used to differentiate MD from AL or RE. The nature of infiltrating neoplastic cells, characterized by cellular pleomorphism comprising lymphocytes, lymphoblasts, macrophages, and neutrophils, was similar in all affected organs, and suggestive of MD. However, RE may present similar histological changes. Therefore, further study is recommended to determine the different avian neoplastic disease viruses infecting chickens in Nigeria, using specific diagnostic tools, such as immunohistochemistry and polymerase chain reaction.

\section{DECLARATIONS}

\section{Acknowledgments}

Many thanks go to MI Waziri, A Yakubu, and D Oshadu, whose close relationship with the farm owners/managers assisted a great deal in getting the cooperation of the farm owners/managers. Our appreciation also goes to late Bitrus Bako of blessed memory for his assistance with the preparation of the histopathology slides. Special thanks to MD Areo for proofreading the manuscript.

\section{Authors' contributions}

All authors contributed equally to this work. NAS, SBO, PAA, and CN conceptualized the work. NAS, CIU, SEA, AS, and MSM participated in the collection, processing, and analysis of data. NAS drafted the manuscript while CIU, SEA, AS, MSM, SBO, PAA, and CN critically revised the manuscript for important intellectual content. All authors approved the final version of the manuscript for publication.

\section{Competing interests}

The authors declare that they have no competing interests.

\section{Consent to publish \\ Not applicable}

Ethics and consent to participate

Not applicable

\section{REFERENCES}

(NIPC) Nigerian Investment Promotion Commission (2019). Nigeria States: Plateau State. Available at: https://www.nipc.gov.ng/nigeriastates/plateau-state/

Abdel-Latif MM, and Khalafalla AI (2005). Detection by PCR of multiple subgroups of avian leukosis virus (ALV) in broilers in the Sudan. Journal of Animal and Veterinary Advances, 4(3): 407-413. Available https://medwelljournals.com/abstract/?doi=javaa.2005.407.413

Abreu DLC, Santos FF, Jose DS, Tortelly R, Nascimento ER, and Pereira VLA (2016). Pathological aspects of a subclinical Marek's disease case in free-range chickens. Brazilian Journal of Poultry Science,
18(1): 197-200. DOI: http://dx.doi.org/10.1590/18069061-2015$\underline{0001}$

Adedeji AJ, Abdu PA, Luka PD, Owoade AA, and Joannis TM (2017). Application of loop-mediated isothermal amplification assay in the detection of herpesvirus of turkey (FC 126 strain) from chicken samples in Nigeria. Veterinary World, 10(11): 1383-1388. Available at: https://www.veterinaryworld.org/Vol.10/November2017/17.pdf

Adedeji AJ, Sati NM, Pewan SB, Ogbu KI, Adole JA, Lazarus DD, Jjiwo SJ, Okpanachi A, Nwagbo IO, Joannis TM et al. (2016). Concurrent infections of chicken infectious anemia and infectious bursal disease in 5 weeks old pullets in Jos, Plateau State, Nigeria. Veterinary Sciences: Research and Reviews, 2(3): 60-65. DOI: http://dx.doi.org/10.17582/journal.vsrr/2016.2.3.60.65

Aughey E, and Frye FL (2001). Preparation of tissue sections. In: Comparative Veterinary Histology with Clinical Correlates, 1st Edition. Mason Publishing Limited, pp. 10-15. Available at: https://www.routledge.com/Comparative-Veterinary-Histologywith-Clinical-Correlates/Aughey-Frye/p/book/9781840761481

Brown C (2012). Using gross pathology to inform diagnostics. In: A Field Manual for Collection of Specimens to Enhance Diagnosis of Animal Diseases, pp. 85-98. Available at: http://vet.uga.edu/oldvpp/programs/afvet/attachments/using_gross_ pathology_to_inform_diagnostics.pdf

Cheng Z, Liu J, and Zhang L (2010). Tumors associated with avian leukosis virus subgroup $J$ in layer hens during 2007 to 2009 in China. Journal of Veterinary Medical Science, 72(8): 1027-1033. Available at: https://www.jstage.jst.go.jp/article/jvms/72/8/72 090564/_pdf

Cheng Z, Zhang H, Wang G, Liu Q, Liu J, Guo H, and Zhou E (2011). Investigation of avian leukosis virus subgroup $\mathrm{J}$ and reticuloendotheliosis virus infection in broiler breeders in China. Israel Journal of Veterinary Medicine, 66(2): 34-38. http://www.ijvm.org.il/node/151

Collett SR, Smith JA, Boulianne M, Owen RL, Gingerich E, Singer RS, Johnson TJ, Hofacre CL, Bergaus RD, and Stewart-Brown B (2020). Chapter I: Principles of Disease Prevention, Diagnosis, and Control. Diseases of Poultry, 14th Edition. John Wiley and Sons, Inc Publishing, Ames Iowa, USA, pp. 1-78. DOI: http://dx.doi.org/10.1002/9781119371199

Denbow DM (2000). Gastrointestinal anatomy and physiology. In: G.C. Whittow (Editor), Sturkie's Avian Physiology, 5th edition. Academic Press, New York, USA, pp. 299-325. Available at: https://www.elsevier.com/books/sturkies-avianphysiology/whittow/978-0-12-747605-6

Dong X, Zhao P, Li W, Chang S, Li J, Li Y, Ju S, Sun P, Meng F, Liu J et al. (2015). Diagnosis and sequence analysis of avian leukosis virus subgroup $\mathrm{J}$ isolated from Chinese Partridge Shank chickens. Poultry Science, 94(4): 668-672. DOI: https://www.doi.org/10.3382/ps/pev040

Duguma R, Yami A, Dana N, Hassen F, and Esatu W (2005). Marek's disease in local chicken strains of Ethiopia reared under confined management regime in central Ethiopia. Revue de Medicine Veterinaire, 156(11): 541-546. Available at: https://www.revmedvet.com/2005/RMV156 541 546.pdf

El-Sebelgy MM, Ahmed BM, Ata NS, and Hussein HA (2014). Molecular detection and characterization of reticuloendotheliosis virus in broiler breeder chickens with visceral tumors in Egypt. International Journal of Veterinary Science and Medicine, 2(1): 2126. DOI: https://dx.doi.org/10.1016/j_ijvsm.2013.12.005

Gao Y, Guan X, Liu Y, Li X, Yun B, Qi X, Wang Y, Gao H, Cui H, Liu $\mathrm{C}$ et al. (2015). An avian leukosis virus subgroup $\mathrm{J}$ isolate with a Rous sarcoma virus like 59-LTR shows enhanced replication capability. Journal of General Virology, 96: 150-158. DOI: https://www.doi.org/10.1099/vir.0.071290-0 
Gao Y, Yun B, Qin L, Pan W, Qu Y, Liu Z, Wang Y, Qi X, Gao H, and Wang X (2012). Molecular epidemiology of avian leukosis virus subgroup $\mathbf{J}$ in layer flocks in China. Journal of Clinical Microbiology, 50(3): 953-960. DOI: https://www.doi.org/10.1128/JCM.00956-12

Gao YL, Qin LT, Pan W, Wang YQ, Qi XL, Gao HL, and Wang XM (2010). Subgroup J avian leukosis virus in layer chickens. China. Emerging Infectious Diseases, 16: 1637-1638. DOI: https://www.doi.org/10.3201/eid1610.100780

Haq AU, Siddique M, and Iqbal Z (2001). Epidemiological study of Marek's disease in commercial layer flocks in district Toba Tek Singh. Pakistan Veterinary Journal, 21(4): 198-201. Available at: http://www.pvj.com.pk/pdf-files/21 4/198-201.pdf

Jwander LD, Abdu PA, Ibrahim NDG, and Nok AJ (2013). Retrospective studies of Marek's disease diagnosed in some towns in Nigeria, 2000-2009. Journal of Veterinary Advances, 3(7): 203-210. DOI: https://www.doi.org/10.5455/JVA.20130722062045

Jwander LD, Abdu PA, Owoade AA, Ekong PS, Ibrahim NDG, and Nok AJ (2012). Molecular detection of Marek's disease virus in avian species from North central Nigeria. Vom Journal of Veterinary Science, 9: 77-82. Available at: https://www.bibliomed.org/?mno=35867

Kaduna State (2019). Available at: http://www.nigeria.gov.ng/index.php/2016-04-06-08-39-54/northwest/kaduna-state

Mbuko IJ, Musa WI, Ibrahim S, Sa'idu L, Abdu PA, Oladele SB, and Kazeem HM (2010). A retrospective analysis of infectious bursal disease diagnosed at Poultry Unit of Ahmadu Bello University, Nigeria. International Journal of Poultry Science, 9(8): 784-790. DOI: https://www.doi.org/10.3923/ijps.2010.784.790

Meng F, Li Q, Zhang Y, Zhang Z, Tian S, and Cui Z (2018). Characterization of subgroup $\mathrm{J}$ avian leukosis virus from Chinese indigenous chickens. Virology Journal, 15: 33. DOI: https://www.doi.org/10.1186/s12985-018-0947-1

Mitra N, Verma R, and Singh A (2013). Early detection of avian oncogenic viruses from blood of apparently healthy chickens. Proceedings of the National Academy of Sciences, India, 83(1): 5358. DOI: https://www.doi.org/10.1007/s40011-012-0084-3

Musa IW, Bisalla M, Mohammed B, Sa'idu L, and Abdu PA (2013). Retrospective and clinical studies of Marek's disease in Zaria, Nigeria. Journal of Bacteriology Research, 5(2): 13-21. DOI: https://www.doi.org/10.5897/JBR12.027

Nigeria Galleria (2015). Kaduna State, Nigeria. Available at: http://www.nigeriagalleria.com/Nigeria/States_Nigeria/Kaduna_Sta te.html

Okonkwo C (2015). An outbreak of Marek's disease in adult layer chickens in Umuahia, Abia State, Nigeria. Annual Research and Review in Biology, 7(3): 200-205. DOI: https://www.doi.org/10.9734/ARRB/2015/18418

Okoye JOA, Ezema W, and Agoha JN (1993). Naturally occurring clinical reticuloendotheliosis in turkeys and chickens. Avian Pathology, 22(2): 237-244. https://www.doi.org/10.1080/03079459308418917

Okwor EC, and Eze DC (2011). Outbreak and persistence of Marek's disease in batches of birds reared in a poultry farm located in Nsukka, South East Nigeria. International Journal of Poultry
Science, $\quad 10(8)$ : $\quad 617-620 . \quad$ DOI: https://dx.doi.org/10.3923/ijps.2011.617.620

Palya V, Benyeda J, and Suveges T (2000). Observations on subgroup J avian leukosis virus infection: Occurence and economic impact of the disease in meat type breeder flocks. Hungarian Veterinary Journal, $\quad 8$ : 460-469. Available at: https://www.semanticscholar.org/paper/Observations-on-subgroupJ-avian-leukosis-virus-and-PalyaBenyeda/ab0da50d409bd141bb208764af58b9d491f526c0

Payne LN, and Venugopal K (2000). Neoplastic diseases: Marek's disease, avian leukosis and reticuloendotheliosis. Review Science Technical, Office of International Epizootics, 19: 544-564. Available at: https://www.oie.int/doc/ged/D9316.PDF

Plateau State (2019). Available at: http://www.nigeria.gov.ng/index.php/2016-04-06-08-39-54/northcentral/plateau-state

Sani NA, Aliyu HB, Musa IW, Wakawa AM, Abalaka SE, Oladele SB, Sa'idu L, and Abdu PA (2017). A nine-year retrospective study of avian neoplastic diseases in Zaria, Kaduna state, Nigeria. Sokoto Journal of Veterinary Sciences, 15(1): 36-41. DOI: http://dx.doi.org/10.4314/sokjvs.v15i1.5

Sun G, Zhang Y, Zhou L, Lv H, Zhang F, Li K, Gao Y, Qi X, Cui H, Wang Y et al. (2017). Co-infection with Marek's disease virus and reticuloendotheliosis virus increases illness severity and reduces Marek's disease vaccine efficacy. Viruses, 9(6): 158. DOI: https://www.doi.org/10.3390/v9060158.

Tian M, Zhao Y, Lin Y, Zou N, Liu C, Liu P, Cao S, Wen X, and Huang $Y$ (2011). Comparative analysis of oncogenic genes revealed unique evolutionary features of field Marek's disease virus prevalent in recent years in China. Virology Journal, 8: 121. Available at: https://www.virologyj.biomedcentral.com/track/pdf/10.1186/1743$\underline{422 X-8-121 . p d f}$

Wakawa AM, Muhammad ZK, Aliyu HB, and Mohammed B (2012). A retrospective analysis of Marek's disease diagnosed at Poultry Clinic of Ahmadu Bello University, Zaria, Nigeria. Journal of Veterinary Advances, 2(8): 424-429. Available at: https://www.semanticscholar.org/paper/A-Retrospective-Analysisof-Marek\%E2\%80\%99s-Disease-at-of-WakawaMuhammad/a31ea2755142aab8860ab0ee91eab0d5ba49732f

Wang G, Jiang Y, Yu L, Wang Y, Zhao X, and Cheng Z (2013). Avian leukosis virus subgroup $\mathrm{J}$ associated with the outbreak of erythroblastosis in chickens in China. Virology Journal, 10: 92. DOI: https://www.doi.org/10.1186/1743-422X-10-92

Zeghdoudi M, Aoun L, Merdaci L, and Bouzidi N (2017). Epidemiological features and pathological study of avian leukosis in turkeys' flocks. Veterinary World, 10(9): 1135-1138. DOI: https://www.doi.org/10.14202/vetworld.2017.1135-1138

Zeng T, Xie Z, Xie L, Deng X, Xie Z, Luo S, Huang L, and Huang J (2015). Simultaneous detection of eight immunosuppressive chicken viruses using a GeXP analyser-based multiplex PCR assay. $\begin{array}{llll}\text { Virology Journal, } & 12 \text { : } 226 . & \text { DOI: }\end{array}$ https://www.doi.org/10.1186/s12985-015-0455-5

Zhang Y, Cui N, Han N, Wu J, Cui Z, and Su S (2017). Depression of vaccinal immunity to Marek's disease by infection with chicken infectious anemia virus. Frontiers in Microbiology, 8: 1863. DOI: https://www.doi.org/10.3389/fmicb.2017.01863 